\title{
Applying seed germination studies in fire management for biodiversity conservation in south-eastern Australia
}

\author{
Tony D. Auld and Mark K. J. Ooi
}

Auld, T. D. and Ooi, M. K. J. 2008. Applying seed germination studies in fire management for biodiversity conservation in south-eastern Australia. - Web Ecol. 8: 47-54.

\begin{abstract}
We examine the patterns of germination response to fire in the fire-prone flora of the Sydney basin, south-eastern Australia, using examples from several decades of research. The flora shows a strong response to fire-related germination cues. Most species show an interaction between heat and smoke, a number respond only to heat, whilst a few are likely to respond only to smoke. Many recruit in the first 12 months after fire and show no obvious seasonal patterns of recruitment, whilst several species have a strong seasonal germination requirement, even in this essentially aseasonal rainfall region. Key challenges remaining include designing future seed germination studies within the context of informing the germination response surface to smoke and heat interactions, and incorporation of the impact of varying soil moisture on seed germination post-fire, including its affect on resetting of seed dormancy. An understanding of the resilience of species to frequent fire also requires further work, to identify species and functional types most at risk. This work must ideally be integrated within the framework of the management of fire regimes that will change under a changing climate. We suggest that the functional classification of plant types in relation to fire could be enhanced by a consideration of both the type of germination response to fire (type of cues required) and the timing of the response (seasonally driven in response to seed dormancy characteristics, or independent of season). We provide a simplified version of such an addition to functional trait classification in relation to fire.
\end{abstract}

T. D. Auld (tony.auld@environment.nsw.gov.au) and M. K. J. Ooi, Dept of Environment and Climate Change NSW, PO Box 1967, Hurstville, NSW 2220, Australia. MKJO also at: Dept of Animal and Plant Sciences, Alfred Denny Building, Univ. of Sheffield, Sheffield S10 2TN, UK.
Fire management is a complex interaction of decisions incorporating the major elements of protection of human life and property and the long-term conservation of biodiversity. The management of biodiversity in fire-prone areas is dependent upon the understanding of how components of the fire regime interact and impact on plants and animals. For plants, much effort has gone into developing simple fire response classifications (Gill 1981, Gill and Bradstock 1992, Pausas 1999, Pausas and Lavorel 2003, Pausas et al. 2004) and gaining an understanding of how critical components of the fire regime, such as fire frequen- cy, may influence species persistence (Gill and McCarthy 1998, Whelan 2002, Pausas and Bradstock 2007). However, the understanding of the significant component of species in fire-prone floras that have a soil-stored seed bank is limited, and may be poorly addressed in simple fire-response classifications. The conservation management of this large group of species in relation to fire has usually been dealt with simply in terms of whether or not species have an ability to resprout (seeders versus sprouters) (Gill and Bradstock 1992). The nature of propagule persistence (Pausas et al. 2004) and the application of seed bank types 
(canopy, soil persistent, soil transient) (Keith et al. 2007) have also been considered. For both sprouters and seeders, the impact of fires and the fire regime on recruitment will have a major influence on persistence in the long term, as seed germination is often cued to fire (Keeley 1987, Auld and O'Connell 1991, Bell 1999, Paula and Pausas 2008). Consequently, understanding how components of the fire regime influence recruitment from seed is a key issue for fire management and biodiversity conservation.

The role of fire and seed germination has largely been derived from laboratory studies and observations of postfire flushes of germination in the field. Laboratory studies on how fire may affect seed germination have focussed on germination cues such as heat and smoke and their interaction with seed dormancy characteristics (Keeley 1987, Auld and O'Connell 1991, Brown 1993, Dixon et al. 1995, Keeley and Fotheringham 1998, Ooi et al. 2006, Merritt et al. 2007, Ooi 2007, Thomas et al. 2007) or resprouting capacity (Paula and Pausas 2008). Most studies have limited replication across the fire cues and often do not examine interactive effects (Thomas et al. 2007). In this context we need to consider the response surface (sensu Thomas et al. 2007) that represents the germination response of seeds over the full range of temperatures, durations of heating and smoking, and smoke concentrations likely to be experienced in the field. Currently most studies only address a small subset of this response surface and a synthesis of the implications of such studies may be limited by the lack of understanding of the germination across the full response surface. Field studies have clearly indicated strong post-fire germination in many taxa in fireprone habitats (Tyler 1995, 1996, Auld and Tozer 1995, Keith et al. 2002). What is more limited is a clearer understanding of the relative seasonal timing of emergence (cf. Ooi et al. 2004, Ooi 2007) and the proportion of the seed bank that emerges versus the proportion that persists in the soil (Auld and Denham 2006).

In this paper, we examine data from over two decades of intensive research into fire-related germination cues of species from the Sydney basin region in south-eastern Australia. We: 1) ask whether existing studies can be used to inform management for biodiversity conservation in a fire-prone region which has strong competing needs for the protection of human life and property, 2) examine how such studies may have influenced fire management in fire-prone habitats in eastern Australia and where further refinement may be necessary, and 3) highlight those areas that urgently require future research to aid conservation management.

\section{The Sydney basin flora}

We collected information from a broad range of studies, summary papers and reports that addressed the impacts of fire on germination in plants from fire-prone habitats of the Sydney basin, south-eastern Australia. This area is a major fire-prone region in eastern Australia and includes the urban metropolis of Sydney with a population of over 5 million people and associated infrastructure. This information was integrated with current fire management practices in this area.

Within the Sydney basin, there is a rich and diverse flora. There are some 2000 plant species that occur in fireprone habitats including a number of endemic species and species considered to be threatened. The vegetation at any one location is made up of a mixture of sprouter and seeder species. Approximately $10 \%$ of all species have a canopy seed bank (including Banksia, Hakea, Allocasuarina and Callitris). In the order of $15 \%$ of species (although this figure may be higher) have no seed bank at the time of a fire, instead they resprout after fire and then flower and produce a transient seed bank (often called obligate resprouters). These contain a number of members of the Liliaceae (sensu lato) as well as some shrubby species of Angophora, Lomatia and Telopea. The great majority of species in fireprone habitats (approximately 75\%) have soil seed banks with some level of seed persistence. In these species there is a germination response in relation to fire cues. For the obligate seeders this is necessary for population persistence post-fire, while for the facultative resprouters successful recruitment from seeds may not be necessary after each fire, given the ability of adult plants to regrow after fire. The proportion of sprouters/seeders in the Sydney basin region is around $0.52 / 0.48$, although in many other fireprone regions the obligate seeding proportion is generally much lower (Pausas et al. 2004). In the Sydney basin, species with persistent soil seed banks belong to a range of plant families, and examples include Fabaceae (Acacia, Dillwynia and Pultenaea), Rutaceae (Boronia, Philotheca), Ericaceae (Epacris, Leucopogon), Myrtaceae (Baeckea, Kunzea), Poaceae (Eragrostis, Microlaena) and Proteaceae (Grevillea, Persoonia).

\section{Managing fire frequency}

Fire in the Sydney basin region is influenced by a variety of factors, including the extensive reserve network of flammable vegetation on poor nutrient soils, past clearing, weed encroachment (particularly where there has been nutrification near urban centres, Thompson and Leishman 2005) and the impact of a changing climate. Fire management for biodiversity conservation has concentrated on two aspects based on available data. Firstly, species have been classified according to their fire response (Gill and Bradstock 1992). Secondly, high fire frequency has been listed in the state of New South Wales (NSW) as a key threatening process (NSW Scientific Committee 2000) and, in response, fire-management attention has focussed on identifying minimal fire-free intervals that are required by species and assemblages of species. One such example 
is the genus Persoonia (Proteaceae). This group contains approximately 35 taxa in the Sydney basin (Weston 2002), of which some $76 \%$ are seeders. A number of these seeders are listed as threatened (Table 1). Where data are available, time to first flowering (primary juvenile period) may take 3-10 years (Benson 1985, Table 1), well beyond many co-habiting species (Keith et al. 2002). However, data for many species are lacking (Table 1). For most species, there is little flowering at the time of first maturity (Auld et al. 2007) and it takes several more years for peak seed production to be reached. For several species, this means that most seed production occurs at an age double that of the primary juvenile period (NSW National Parks and Wildlife Service 2000, Auld et al. 2007). The average fire return interval for these habitats is 7-17 years (Bradstock and Kenny 2003) and fires may occur at a frequency as high as every 5 years, particularly where arson or fire management for protection of human life and property oc- cur. Fire management for threatened Persoonia species has consequently set minimum fire return intervals of over a decade (Table 1) in order to reduce the risk of fire-driven population declines or extinctions.

\section{Seed germination cues and fire}

Germination studies in south-eastern Australia have focussed primarily on the impacts of heat and smoke alone, and more recently on the interaction of these two factors. Few studies have attempted to examine the full germination response surface across the breadth of the fire cues, with most simply testing a small component of it, i.e. a single temperature and duration of heating, or a single smoke concentration. Three groupings of species responses are apparent. Firstly, there are a number of predominately hard seeded species where the degree of heating controls

Table 1. Fire response and time to maturity in Persoonia species from the Sydney basin (data compiled from Benson and McDougall 2000, NSW National Parks and Wildlife Service fire response register 2002, T. D. Auld unpubl.). Threat status: en - endangered, vu - vulnerable. The minimum fire-free interval is the recommended interval between fires that must be allowed for species persistence (from NSW Rural Fire Service 2006, T. D. Auld unpubl.).

\begin{tabular}{|c|c|c|c|c|}
\hline Species & $\begin{array}{l}\text { Fire } \\
\text { response }\end{array}$ & $\begin{array}{l}\text { Threat } \\
\text { status }\end{array}$ & $\begin{array}{l}\text { Primary } \\
\text { juvenile period } \\
\text { (years) }\end{array}$ & $\begin{array}{l}\text { Minimum } \\
\text { fire-free } \\
\text { interval (years) }\end{array}$ \\
\hline P. acerosa & seeder & $\mathrm{vu}$ & $?$ & $10+$ \\
\hline P. acuminata & $?$ & not threatened & $?$ & $?$ \\
\hline P. bargoensis & seeder & en & $?$ & $10+$ \\
\hline P. chamaepeuce & sprouter & unknown & $?$ & $?$ \\
\hline P. chamaepitys & seeder & not threatened & $?$ & $?$ \\
\hline P. glaucescens & seeder & en & $?$ & $15+$ \\
\hline P. hindii & sprouter & en & $?$ & $10+$ \\
\hline P. hirsuta & seeder & en & $?$ & $10+$ \\
\hline P. isophylla & seeder & not threatened & $3-7+$ & $10+$ \\
\hline P. Lanceolata & seeder & not threatened & $3-7+$ & $10+$ \\
\hline P. laurina & sprouter & unknown & $?$ & $?$ \\
\hline P. laxa & seeder & extinct & $?$ & $?$ \\
\hline P. levis & sprouter & not threatened & $7+$ & $10+$ \\
\hline P. linearis & sprouter & not threatened & $?$ & $?$ \\
\hline P. marginata & sprouter & $\mathrm{vu}$ & $?$ & $10+$ \\
\hline P. microphylla & $?$ & unknown & $?$ & $?$ \\
\hline P. mollis & seeder & en (subspecies) & $8-10$ & $12+$ \\
\hline P. myrtilloides & seeder & unknown & $?$ & $?$ \\
\hline P. nutans & seeder & en & $?$ & $10+$ \\
\hline P. oblongata & seeder & enknown & $?$ & $?$ \\
\hline P. oxycoccoides & sprouter & rare & $?$ & $?$ \\
\hline P. pauciflora & seeder & en & $?$ & no fire \\
\hline P. pinifolia & seeder & not threatened & $5-8+$ & $12+$ \\
\hline P. recedens & $?$ & rare & $?$ & $?$ \\
\hline P. rigida & seeder & unknown & $?$ & $?$ \\
\hline
\end{tabular}


Table 2. Incorporation of fire related seed germination strategies into a functional classification of plants. This level of classification would sit below the distinction between persistent and transient seed banks under each of the seeder and sprouter categories.

\begin{tabular}{llll}
\hline $\begin{array}{l}\text { Seed bank } \\
\text { type }\end{array}$ & $\begin{array}{l}\text { Fire response } \\
\text { cues }\end{array}$ & $\begin{array}{l}\text { Seasonal fire } \\
\text { response }\end{array}$ & $\begin{array}{l}\text { Comments/examples } \\
\text { from Sydney basin }\end{array}$ \\
\hline $\begin{array}{l}\text { Soil } \\
\text { transient }\end{array}$ & none & no & $\begin{array}{l}\text { common, liliaceae sensu lato } \\
\text { Angophora, Doryanthes, } \\
\text { Lomatia, Telopea, Xanthorrhoea }\end{array}$ \\
Soil & hes & no & unknown \\
persistent & common, Fabaceae & rare/unknown \\
& smoke only & no & uncommon \\
& currently unknown but likely
\end{tabular}

the breaking of seed dormancy. In the Sydney basin, this represents some 250 species (12-15\% of total flora) and includes most legumes (Fabaceae) and Dodonaea species (Sapindaceae) (Floyd 1966, 1976, Auld and O'Connell 1991, Keith 1996, Ooi 2007; Table 2). For these species, during a fire, the magnitude and duration of soil heating will decline with soil depth (Fig. 1). This is because soil heating is influenced by the consumption of fine fuels at the soil surface during the passage of a fire (Bradstock and Auld 1995) and the soil has insulating properties. Secondly, there has been a more limited examination of permeable seeds and seeds with physiological dormancy. Such species often have germination enhanced by smoke or the combination of heat and smoke (e.g. Ericaceae, Rutaceae and a number of small seeded Myrtaceae, e.g. Kunzea). Whilst only a small proportion $(<10 \%$ of the total flora) are thought to respond to smoke alone (Kenny 2003), we estimate that approximately 900 species $(25-45 \%$ of the total flora) have complex smoke $\times$ heat interactions (Keith 1997, Kenny 2000, 2003, Morris 2000, Thomas et al. 2003, 2007, Ooi et al. 2004, Clarke and French 2005). For these species, the relationship between fire-cues and soil depth is less certain. A depth related response is expected for species with interactions between heat and smoke (due to declines in heating with increasing soil depth). For those species with germination enhanced by a smoke effect only, the smoke cue may operate independently of soil depth or have some other relationship with soil depth (Fig. 1 ), although this remains to be explored.

Finally, there are a number of taxa that currently show no response to fire cues, or have a response that is essentially unknown. Much of this is primarily because of the limited understanding of physiological dormancy and fire cues. Although dormancy has not been precisely classified for many taxa, it is very likely that more than 200 species (10\% of the total flora, e.g. Hibbertia, Persoonia, Rutaceae, Apiaceae, many Ericaceae, Ooi et al. 2004, Ooi 2007) have a physiological dormancy component. For many of these taxa, a response to either heat or smoke alone has been documented but is often variable, and the response is often not an obligate one. Additionally, as for many other species, the full response surface has not been examined. We consider it likely that the taxa which are difficult to germinate from seed, or have poorly known germination

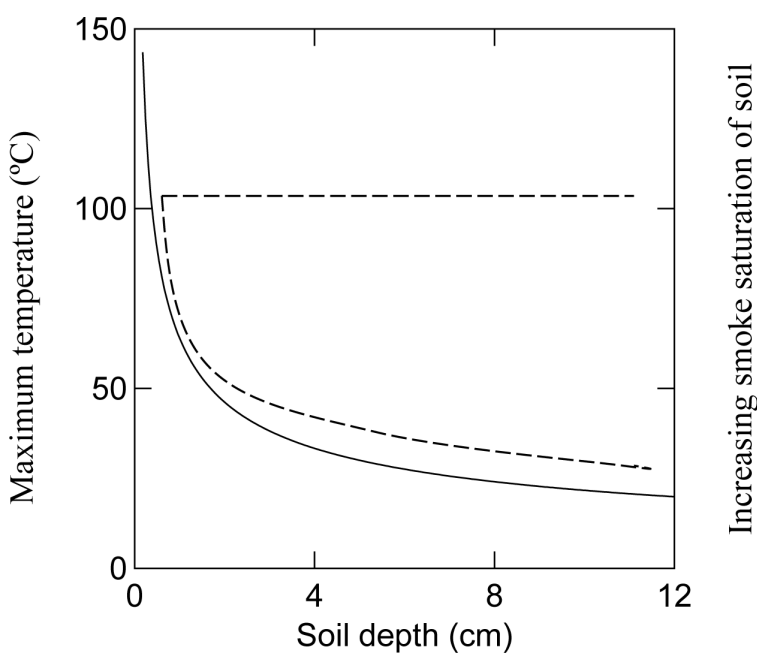

Fig. 1. Possible variation of fire cues with soil depth. Solid line - heat profile from a typical wildfire (T. D. Auld unpubl.). The dashed lines represent a range of possible relationships between smoke concentration and soil depth, varying from complete saturation at all depths (horizontal line) to a rapid decline in saturation with soil depth. 
mechanisms, are those that have a physiological dormancy component (e.g. physiological, morphophysiological or physical + physiological dormancy classes), as is expected for many difficult to germinate species from Western Australia (Merritt at al. 2007).

\section{Seasonal impacts on germination}

For a number of taxa (some 15-30\% of the flora) there are no seasonal requirements for germination (Table 2), independent of the fire cue that promotes germination. Most Fabaceae falls into this group. Unlike fire-prone habitats in Mediterranean regions, rainfall is more or less evenly spread across seasons in the Sydney basin. As a consequence, fires and opportunities for post-fire recruitment can occur at any time in this region. In contrast, a few species are known to only germinate in a certain season (Table 2). They have specific temperature needs for either embryo maturation and/or germination eg. all Leucopogon species (Ericaceae) (Ooi et al. 2004). Like Leucopogon spp., a number of species have a strong seasonal temperature re- quirement for germination (e.g. Kunzea spp., Baeckea spp., Epacris spp., Drachophyllum spp., Goodenia spp., Thomas 2004). In fire-prone Mediterranean systems, this seasonal response is expected to be the predominant functional type, given the lack of available moisture in summer.

In addition, whilst fire may promote germination, dormancy may need to be broken initially by seasonal temperatures. A seasonal cue could effectively reset dormancy or prevent germination outside a particular seasonal window. This seasonal requirement can override the fire-related germination cues, e.g. Kunzea spp. (Auld et al. 2000, Thomas 2004, Ooi 2007, Merritt et al. 2007) and, as a consequence, the germination of species with strong seasonal requirements may be delayed post-fire relative to those species with no seasonal requirement (Fig. 2). This could give a competitive advantage, under certain fire regimes, to species with no seasonal requirement for germination. The competitive disadvantage in species whose emergence is tied to a season would potentially result from both the delay in seedling emergence, as well as the reduced magnitude of emergence (Fig. 2), e.g. via seed decay or seed predation over the delayed period.

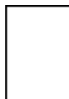

no seasonal germination

seasonal germination

\section{seasonal germination with decline over time or induced secondary dormancy}

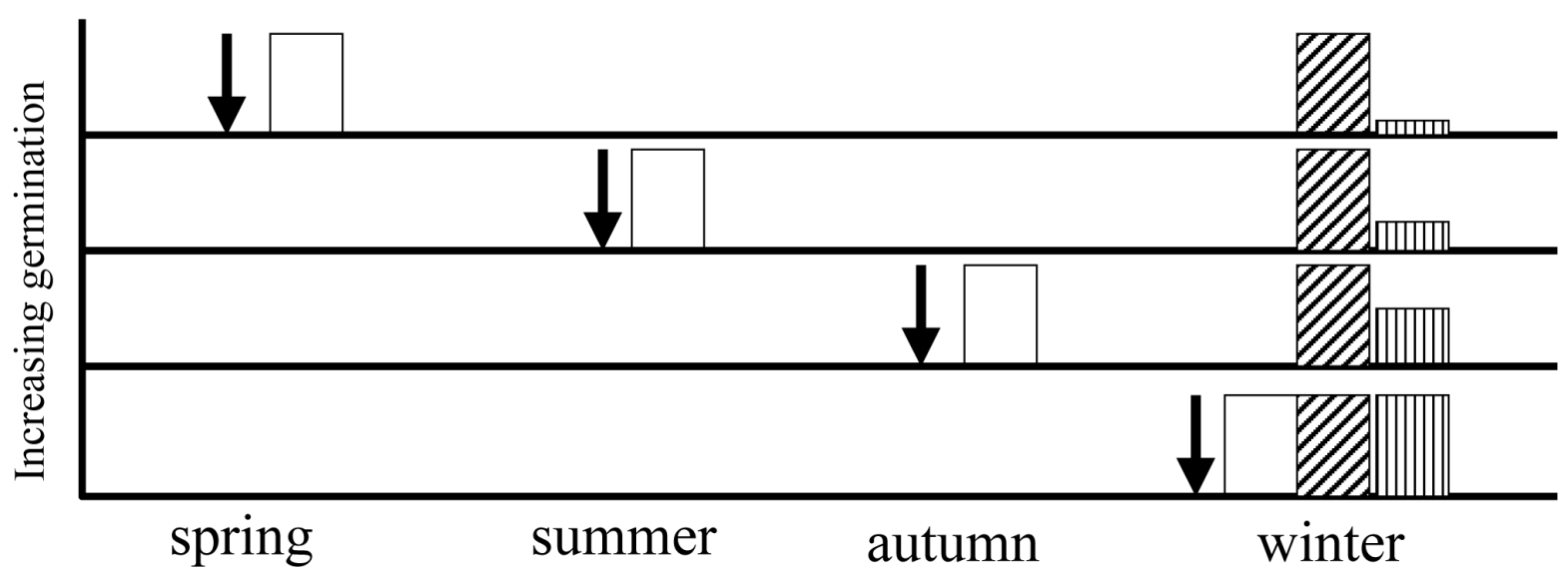

Fig. 2. Impact of season of burn on resultant seedling germination for three classes of species: no seasonal germination impacts (open bars); seasonal germination (sloped hatching); and seasonal germination that declines with the length of time since fire with respect to the favourable season for germination (vertical hatching). Arrows represent four postulated fires (one for each season). The germination level after fires in different seasons is staggered for clarity. 


\section{Further research}

Most studies of relevance to plant recruitment and fire have either dealt with monitoring the magnitude of species composition after fire or examining germination cues in laboratory studies. These studies illustrate that there is a definite pulse of germination after fire in a broad array of plant species from many different plant families (Keith 1996, Keith et al. 2002). Most recruitment is also confined to soon after fire in non Mediterranean eastern Australian systems (Auld and Tozer 1995, Keith et al. 2002), where rainfall is not strongly seasonal. At the same time, there are some taxa with forms of physiological dormancy that may have delayed emergence, relative to the majority of cohabiting species, with the timing of emergence dependant upon the season of fire (Ooi 2007). More data is needed to determine just how widespread and abundant species with a seasonal germination response are in the wild in this study region.

Laboratory studies have highlighted the importance of both heat and smoke as fire related cues that either break seed dormancy or enhance seed germination. However, our understanding of species responses to fire regimes is still somewhat fragmented and a number of key knowledge gaps remain. Firstly, the development of an understanding of the germination response surface of a species to interactive fire cues needs to be extended. A solid framework is in place (Thomas et al. 2007), but a greater range of taxa need to be examined across the whole potential response surface, as opposed to single temperatures, durations of heating and concentrations of exposure to smoke. As well, the role of variation in soil moisture in influencing seed dormancy and the enhancement of germination (particularly by smoke) remains to be incorporated into this framework. This work then urgently needs to be experimentally tested in the field in experimental fires to determine if the complexity in the laboratory is mirrored in the field. Secondly, the examination of the nature of the resilience of species with soil seed banks to frequent fire is in its infancy. Broad scale generalisations are currently not possible, although there may be patterns that relate directly to seed morphology and the types of fire-related cues that promote germination (Auld and Denham 2006, Auld et al. 2007, Ooi 2007).

Finally, the transfer of practical information to fire managers has essentially concentrated on aspects of fire frequency. Although fire management has applied the concept of variation in fire regimes, therefore addressing fire severity and patchiness to some extent, the significance of other components of the fire regime are still poorly known and little applied. For example, the amount of soil heating during a fire appears to be a good indicator of post-fire germination in hard-seeded (or physically dormant) species and fire managers in eastern Australia have attempted to have variation in local fire severity to encourage recruitment from species that respond to heat. However, fire sea- son impacts, predicted from laboratory studies (Ooi 2007), are currently largely outside the fire management focus. In addition, fire impacts may be distorted by limiting managed fires to cooler and wetter months when fire can be effectively controlled, even though this may fall outside the historical fire regime (McLoughlin 1998). Given the likely changes to fire regimes under a changing climate (Cary et al. 2006), a more complete understanding of the interaction of components of the fire regimes is warranted.

To this end, it is clear that simple classifications of plants into functional types based on sprouting versus seeding and canopy versus soil seed banks remains of limited use in compiling the complexity of vegetation response to fire. At a minimum, we consider that there is an urgent need to incorporate components of fire-related recruitment into functional classifications. In its simplest form this would incorporate the three basic functional responses identified here (Table 2), i.e. a scaling of fire cues (heat only, smoke only, interaction of heat and smoke) in combination with seed dormancy type (itself a major driver of seasonal responses and the likelihood of resetting dormancy under environmental stresses) and seasonal germination or emergence response.

Acknowledgements - We thank Juli Pausas for constructive comments on this manuscript.

\section{References}

Auld, T. D. and Denham, A. J. 2006. How much seed remains in the soil after a fire. - Plant Ecol. 187:15-24.

Auld, T. D. et al. 2000. Patterns in longevity of soil seedbanks in fire-prone communities of southeastern Australia. - Aust. J. Bot. 48: 539-548.

Auld, T. D. et al. 2007. Dispersal and recruitment dynamics in a fleshy-fruited Proteaceae species (Persoonia lanceolata). - J. Veg. Sci. 18: 903-910.

Auld, T. D. and O'Connell, M. A. 1991. Predicting patterns of post-fire seed germination in 35 eastern Australian Fabaceae. - Aust. J. Ecol. 16: 53-70.

Auld, T. D. and Tozer, M. 1995. Patterns in emergence of Acacia and Grevillea seedlings after fire. - Proc. Linn. Soc. NSW 115: 5-15.

Bell, D. T. 1999. Turner review no. 1 - the process of germination in Australian species. - Aust. J. Bot. 47:475-517.

Benson, D. H. 1985. Maturation periods for fire sensitive shrub species in Hawkesbury sandstone vegetation. Cunninghamia 1: 339-349.

Benson, D. and McDougall, L. 2000. Ecology of Sydney plant species: part $7 \mathrm{~b}$. Dicotyledon families Proteaceae to Rubiaceae. - Cunninghamia 6: 1016-1202.

Bradstock, R. A. and Auld, T. D. 1995. Soil temperatures during bushfires in relation to fire intensity: consequences for legume germination and fire management in south-eastern Australia. - J. Appl. Ecol. 32: 76-84.

Bradstock, R. A. and Kenny, B. J. 2003. An application of plant functional types to fire management in a conservation reserve in south-eastern Australia. - J. Veg. Sci. 14: 345-354. 
Brown, N. A. C. 1993. Promotion of germination of Fynbos seeds by plant-derived smoke. - New Phytol. 123: 575-583.

Cary, G. J. et al. 2006. Comparison of the sensitivity of landscapefire-succession models to variation in terrain, fuel pattern, climate and weather. - Landscape Ecol. 21:121-137.

Clarke, S. and French, K. 2005. Germination response to heat and smoke of 22 Poaceae species from grassy woodlands. Aust. J. Bot. 53: 445-454.

Dixon, K. W. et al. 1995. The promotive effect of smoke derived from burnt native vegetation on seed germination of western Australian plants. - Oecologia 101: 185-192.

Floyd, A.G. 1966. Effect of fire upon weed seeds in the wet sclerophyll forests of northern New South Wales. - Aust. J. Bot. 14: 243-256.

Floyd, A. G. 1976. Effect of burning on regeneration from seeds in wet sclerophyll forest. - Aust. For. 39:210-220.

Gill, A. M. 1981. Adaptive responses of Australia vascular plant species to fires. - In: Gill, A. M. et al. (eds), Fire and the Australian biota. Aust. Acad. Sci., Canberra, pp. 243-272.

Gill, A. M. and Bradstock, R. A. 1992. A national register for the fire responses of plant species. - Cunninghamia 2: 653-660.

Gill, A. M. and McCarthy, M. A. 1998. Intervals between prescribed fires in Australia: what intrinsic variation should apply? - Biol. Conserv. 85:161-169.

Keeley, J. E. 1987. Role of fire in seed germination of woody taxa in California chaparral. - Ecology 68: 434-443.

Keeley, J. E. and Fotheringham, C. J. 1998. Smoke-induced seed germination in California chaparral. - Ecology 79: 2320-2336.

Keith, D. A. 1996. Fire-driven extinction of plant populations: a synthesis of theory and review of evidence from Australian vegetation. - Proc. Linn. Soc. NSW 116: 37-78.

Keith, D. A. 1997. Combined effects of heat shock, smoke and darkness on germination of Epacris stuartii Stapf., an endangered fire-prone Australian shrub. - Oecologia 112: 340-344.

Keith, D. A. et al. 2002. Fire regimes in Australian heath lands and their effects on plants and animals. - In: Bradstock, R. A. et al. (eds), Flammable Australia: the fire regimes and biodiversity of a continent. Cambridge Univ. Press, pp. 199-237.

Keith, D. A. et al. 2007. Plant functional types can predict decade-scale changes in fire-prone vegetation. - J. Ecol. 95: 1324-1337.

Kenny, B. J. 2000. The influence of multiple fire-related germination cues on three Sydney Grevillea (Proteaceae) species. - Austral Ecol. 25: 664-669.

Kenny, B. J. 2003. Fire-related germination cues for soil-stored seedbanks of fire-prone habitats in the Sydney region, Australia. Ph D thesis. - Univ. of Technology, Sydney.

Merrit, D. J. et al. 2007. Seed dormancy and germination stimulation syndromes for Australian temperate species. Aust. J. Bot. 55:336-354.

McLoughlin, L. C. 1998. Season of burning in the Sydney region: the historical records compared with recent prescribed burning. - Aust. J. Ecol. 23: 393-404.

Morris, E. C. 2000. Germination response of seven east Australian Grevillea species (Proteaceae) to smoke, heat exposure and scarification. - Aust. J. Bot. 48: 179-189.

NSW National Parks and Wildlife Service 2000. Persoonia mollis subsp. maxima recovery plan. - NSW NPWS Hurstville,
Sydney. <http://www2.nationalparks.nsw.gov.au/PDFs/ persmol.pdf>, accessed 14 Mar 2008.

NSW National Parks and Wildlife Service 2002. NSW Flora fire response database, ver. 1.3a. - NSW NPWS Hurstville, Sydney.

NSW Rural Fire Service 2006. Bushfire environmental assessment code for asset protection and strategic for advantage zones. <http://www.rfs.nsw.gov.au/dsp_content. cfm?CAT_ID=536>, accessed 18 Mar 2008.

NSW Scientific Committee 2000. Final determination for listings 'high frequency fire resulting in the disruption of life cycle processes in plants and animals and loss of vegetation structure and composition' as a key threatening process under the NSW Threatened Species Conservation Act 1995. <http://www.environment.nsw.gov.au/threatenedspecies/E cologicalConsequencesFiresKTPListing.htm>, accessed 14 Mar 2008.

Ooi, M. K. J. et al. 2004. Seedling emergence patterns of Leucopogon (Epacridaceae) in the fire-prone vegetation of south-eastern Australia: seasonal germination in a nonseasonal rainfall region. - Plant Ecol. 174: 183-196.

Ooi, M. K. J. et al. 2006. Dormancy and the fire-centric focus: germination of three Leucopogon species (Ericaceae) from south-eastern Australia. - Ann. Bot. 98: 421-430.

Ooi, M. K. J. 2007. Dormancy classification and potential dormancy-breaking cues for shrub species from fire-prone south-eastern Australia. - In: Adkins, S. et al. (eds), Seeds: biology, development and ecology. CAB International, pp. 205-216.

Paula, S. and Pausas, J. G. 2008. Burning seeds: germinative response to heat treatments in relation to sprouting ability. J. Ecol. 96: 543-552.

Pausas, J. G. 1999. Response of plant functional types to changes in the fire regime in Mediterranean ecosystems: a simulation approach. - J. Veg. Sci. 10: 717-722.

Pausas, J. G. and Bradstock, R. A. 2007. Fire persistence traits of plants along a productivity and disturbance gradient in mediterranean shrublands of south-east Australia. - Global Ecol. Biogeogr. 16: 330-340.

Pausas, J. G. et al. and The GCTE Network 2004. Plant functional traits in relation to fire in crown-fire ecosystems. - Ecology 85: 1085-1100.

Pausas, J. G. and Lavorel, S. 2003. A hierarchical deductive approach for functional types in disturbed ecosystems. - J. Veg. Sci. 14:409-416.

Thomas, P. B. 2004. Effects of factors associated with the season of a fire on germination of species forming soil seedbanks in the fire-prone Hawkesbury sandstone region of Sydney, Australia. PhD thesis. - Univ. of Western Sydney.

Thomas, P. B. et al. 2003. Interactive effects of heat shock and smoke on germination of nine species forming soil seed banks within the Sydney region. - Austral Ecol. 28: 674-683.

Thomas, P. B. et al. 2007. Response surfaces for the combined effects of heat shock and smoke on germination of sixteen species forming soil seed banks in south-eastern Australia. Austral Ecol. 32: 605-616.

Thompson, V. P. and Leishman, M. R. 2005. Post-fire vegetation dynamics in nutrient-enriched and non-enriched sclerophyll woodland. - Austral Ecol. 30: 250-260.

Tyler, C. M. 1995. Factors contributing to post-fire seedling establishment in chaparral: direct and indirect effects of fire. - J. Ecol. 83: 1009-1020. 
Tyler, C. M. 1996. Relative importance of factors contributing to post-fire seedling establishment in maritime chaparral. Ecology 77: 2182-2195.

Weston, P. H. 2002. Persoonia. - In: Harden, G. J. (ed.), Flora of New South Wales. Vol. 2. Univ. of New South Wales Press, pp. 4-20.
Whelan, R. J. 2002. Managing fire regimes for conservation and protection: an Australian response. - Conserv. Biol. 16: 1659-1661. 